\title{
Factores del Nuevo Plan de Estudios de Derecho 2003, que inciden en la disminución de la matricula y la permanencia en la Facultad de Derecho de la UNAH
}

\author{
Alba Argentina López \\ Profesora Investigadora. Instituto de Investigación Jurídica \\ Universidad Nacional Autónoma de Honduras
}

\section{RESUMEN}

El objetivo de realizar el presente trabajo es conocer cuáles son los factores que han incidido en la disminución de la matrícula y permanencia que se ha producido en la Facultad de Ciencias Jurídicas de la Universidad Nacional Autónoma de Honduras. Para realizar este trabajo de investigación se tomó una muestra de estudiantes de la Carrera de Derecho que estudian con el Plan de Estudios 2003. Después de realizada la investigación se llegó a la conclusión que el Plan de Estudios de la Carrera de Derecho de la Facultad de Ciencias Jurídicas del 2003, si es uno de los factores que inciden en la disminución de la matrícula y la permanencia en la misma.

Palabras clave: Plan de estudios, estudiante, derecho carrera, Universidad Nacional Autónoma de Honduras.

\section{ABSTRACT}

The purpose of this study is to find but the reasons that have influenced the decreasing enrollment and permanence of students at the Faculty of Legal Sciences at the Universidad Nacional Autónoma de Honduras. In order to carry out this research a sample of students who are enrolled in the 2003 program was taken. After completing the investigation, the conclusion is that the 2003 Program os the Law Faculty does play an influence in the decreasing of registration and continuance of students.

Keywords: Curriculum, student, law career, Universidad Nacional Autónoma de honduras. 


\section{INTRODUCCIÓN}

Vivimos en un mundo que día a día cambia, siendo esta la premisa de los procesos de la transformación educativa, estas transformaciones necesitan de cambios e innovaciones, donde el estudiante sea el autor principal de su transformación. Para lograr estas transformaciones es necesario desarrollar las competencias y potencialidades de cada individuo que se involucra en forma activa y participativa en el proceso enseñanza-aprendizaje en la educación superior propiamente dicha.

La presente investigación está dividida en cuatro capítulos, el Primer Capítulo denominado Antecedentes Históricos, donde se hace una referencia breve a la creación de la Carrera de Derecho. El Capítulo segundo denominado El Nuevo Plan de Estudios de Derecho del 2003, donde se hace una descripción mínima del mismo. El Capítulo Tercero hacemos referencia de la matrícula de la carrera de Derecho en la Universidad Autónoma de Honduras, en comparación a la matrícula de Derecho en las Universidades Privadas. El Cuarto y último capítulo nos da la respuesta a la situación de los problemas o Factores del Nuevo Plan de Estudios de la Carrera de Derecho que inciden en la disminución de la matrícula y permanencia en la Facultad de Derecho de la UNAH.

\section{CAPÍTULO I}

\section{ANTECEDENTES HISTÓRICOS}

La carrera de Derecho nace con la misma Universidad en 1847, mediante Decreto emitido por el Doctor Juan Nepomuceno Lindo y Zelaya, teniendo como antecedentes la constitución de la Sociedad del Genio Emprendedor del Buen Gusto, auspiciada por el presbítero José Trinidad Reyes, en donde, además de las asignaturas de gramática, castellano y Latino, Filosofía y Derecho Canónico, se enseñaba ya Derecho Civil.

En 1854 egresan 9 bachilleres en ambos Derechos, o sea Canónico y Civil. En 1854 siendo Presidente el General Santos Guardiola, era profesor de Cánones y Derecho Civil el Dr. Francisco Barberena, como la Dirección de Estudios de la Universidad no podía pagarle, el Gobierno tuvo que darle su sueldo complementándolo el Magistrado Bátelo y el Lic. Crescencio Gómez. 
En 1862 se estableció la cátedra de Derecho Teórico Practico, pero los estudiantes no le daban importancia a las clases de esta asignatura por considerarla útil únicamente a aquellos que estudiaban sacerdocio y ni siquiera se presentaban a exámenes.

En 1869 los alumnos que concurrían a las clases de Derecho Civil eran obligados a cursar las clases de Sagrados Cánones. Para tener el grado en cualquiera de las dos especialidades debían hacer el examen privado de ambos.

En 1869 para obtener el grado de Bachiller en Derecho se realizaban 4 años de estudio en la Universidad; los primeros años eran dedicados al Derecho Civil y Canónico, un año al Derecho Romano, Natural y de Gente y el último al Derecho Constitucional y Economía Política. Los exámenes de graduación públicos y las preguntas las sorteaba el Secretario de la Universidad en presencia del Señor Rector, los textos ' para la enseñanza eran designados por el Rector y aprobados por la Junta Directiva del Consejo de Instrucción Pública. En estos años la Universidad tuvo muchas dificultades económicas y en algunos momentos existió el peligro de que desapareciera a pesar de los esfuerzos del gobierno y de los catedráticos y autoridades universitarias que en varias ocasiones tuvieron que prestar sus servicios en forma gratuita. Solo el Bachiller en Filosofía podía estudiar Derecho. El Bachillerato en Filosofía tenía una duración de 3 años y se estudiaba Física, Matemáticas y Gramática Castellana así como francés o Inglés. Las clases de Física eran las que explicaban la filosofía del siglo XVIII y hasta en 1870 se incluyó el estudio de aritmética y algo de álgebra cuando fue servida por un ingeniero belga. Mientras en América se estudiaba Derecho Civil con el libro del guatemalteco Álvarez, en Honduras se estudiaba de memoria la ilustración del Derecho Real de España por Juan Sala y un compendio de Derecho Español. Del mismo modo se estudiaba el Derecho Canónico por Devoti, libro que sustituyó al de Cabalario. Andaba de mano en mano un compendio del Derecho Español, en preguntas y respuestas, que prestaba mucha utilidad para los exámenes de Derecho Civil; para el Derecho Canónico se consultaba las obras del caballero Don Justo Donoso. Para ser abogado, el alumno, después de obtener su título en Derecho Civil, recibía clases privadas con un profesor durante 3 años: Practica Forense, Ordenanza de Minería, Ordenanzas de Bilbao (de comercio), Leyes Patrias, La constitución Política, Procedimientos Militares y Eclesiástico, Derecho Administrativo, Derecho Político Primero, y luego el Constitucional, Derecho Natural, Derecho de Gente y Retórica Forense. Durante estos estudios el alumno 
hacia su práctica en los tribunales, era examinado para así obtener el título de Abogado.

En 1878 se suprimió las clases de Latinidad y Derecho Teórico Practico, debido al aprendizaje deficiente de los alumnos en la primera y a la indisciplina y negativa a someterse a exámenes de los alumnos de la segunda.

En 1881 con la reforma de Marco Aurelio Soto se creó la Facultad de Jurisprudencia y Ciencias Políticas, dejándose el mero estudio teórico del Derecho y de los materiales religiosos, se confería el grado de licenciado, Se contrata al profesor español Santiago Guerrero López como catedrático de Derecho Romano, en ese momento existía la asignatura de Prolegómenos del Derecho y con un año más de estudio en un curso especial, se podía obtener el Doctorado. Durante el gobierno del Dr. Marco Aurelio Soto, la Universidad logro una estabilidad económica que no había podido obtener antes ya que los fondos que el Estado le tenía destinados eran pagados con toda puntualidad.

En 1890 trajeron al profesor español, Lic. Francisco Martos de la Fuente para que sirviera la clase de Derecho Internacional Público.

En 1895 al renunciar el Lic. Carlos Alberto Ucles de la clase de Derecho Internacional Público, se nombró en su lugar al Dr. Rafael Alvarado Manzano. En 1897 la matrícula de la Facultad fue de 24 alumnos.

En 1903 a las 18 asignaturas del plan de la carrera de Jurisprudencia se le agrega la de Sociología y Literatura Forense, los alumnos del $4^{\circ}$ curso realizaban práctica en los Juzgados de Letras y los de $5^{\circ}$ curso en los Tribunales. Con el nuevo Código de Instrucción de 1906, desapareció la asignatura de Prolegómenos del Derecho y apareció la de Derecho Natural, en 1913 era Decano de la Facultad de Jurisprudencia don Pedro J. Bustillo.

En 1924 fue nombrado Decano de la Facultad al Lic. Leandro Valladares. Debido a la crisis económica en ese año, muchos catedráticos tuvieron que servir las cátedras en forma gratuita.

En 1928 fue cerrado el primer curso de Derecho, debido a incidente entre el Gobierno y la FEUH; permaneciendo cerrada por varios años. 
En 1947 se hicieron reformas al Código de Educación, y la Facultad recibió el nombre de Facultad de Ciencias Jurídicas y Sociales.

En 1953 se emitieron los nuevos estatutos de la Universidad de Honduras, se establecen las obligaciones de los catedráticos y alumnos. Los requisitos establecidos para el ejercicio de la cátedra consistieron en; poseer un título y una buena conducta; la escogencia era hecha después de someterse a un examen de oposición. La Facultad de Derecho siguió funcionando en el edificio del convento de la Merced mientras que las demás facultades fueron trasladadas a los nuevos locales.

En el año de 1957 se obtuvo la autonomía Universitaria, que desde años antes se estaba luchando por conquistar con campañas estudiantiles y con el apoyo de profesionales junto a ciertos sectores políticos.

En 1958 se establece la libre asistencia de alumnos con exámenes mensuales obligatorios; la libre cátedra; se modifica el sistema de enseñanza jurídica, se abre un Consultorio Jurídico atendido por alumnos del último año con asesoría de los profesores correspondientes, que es donde se proporciona la formación práctica a los alumnos que han cumplido los requisitos para realizar su práctica jurídica forense obligatoria la que realizan por un periodo de un año, este fue un servicio a la comunidad, donde la Facultad hacía extensión y proyección social, cuya finalidad era la de auxiliar técnica y prácticamente al pueblo, especialmente en materia civil, criminal y laboral. La Facultad de Ciencias Jurídicas y Sociales contaba ya con biblioteca bien organizada.

En 1960 la matricula en la Facultad ascendió a 372 alumnos se emitió un reglamento provisional para la Facultad que exigía un mínimo de asistencia de los alumnos, exámenes rigurosos, mayor dedicación, y responsabilidad del alumno, pero posteriormente este reglamento quedo en suspenso.

En 1961 Honduras participo en la creación del Instituto Latinoamericano de Derecho Comparado formado por 27 Facultades de Derecho. Ese mismo año se aprobaron los estatutos del Instituto Centroamericano de Derecho Comparado.

En 1963 la matricula fue de 391 alumnos y fueron aprobados por la Junta Directiva de la Facultad un cuerpo docente de 24 profesores, la biblioteca de la Facultad 
siguió funcionado regularmente, y en periodo de examen finales permaneció abierta hasta las dos de la mañana y se hacía canje de la revista de derecho con revistas de otras facultades tanto de América como de España.

En 1964 fue presentado un nuevo proyecto de la Facultad por la Comisión designada para tal efecto, en junio de 1965 se sirvió un curso de Derecho comparado en la Facultad, con la colaboración de la Facultad Internacional para la Enseñanza del Derecho Comparado y el Instituto Centro Americano de Derecho. En ese mismo año el Consejo Universitario aprobó el Reglamento de la Facultad, el que además sirvió a las facultades que en esos momentos no tenían un Reglamento.

En 1966, la Junta Directiva de la Facultad nombró una comisión para hacer la revisión del Anteproyecto de Plan de Estudios presentado por los catedráticos de la Facultad, este nuevo plan fue aprobado en enero de 1967, el plan de estudios de 1967, incluía materias modernas como Sociología del Derecho y Derecho Agrario. El personal Docente lo conformaban 22 catedráticos, también fue creada una Dirección de Seminarios con el objeto de complementar la enseñanza que los alumnos recibían en sus clases normales.

En 1969 fue aprobado por el Consejo Universitario el proyecto de restauración de los estudios de la carrera de Derecho y la aplicación de un plan de estudios menos rígido para los estudiantes de los tres primeros años. Se implanta un nuevo sistema de evaluación y se adecua la estructura académica de la Facultad a una organización departamentalizada, en ese mismo año la Facultad se trasladó a las instalaciones de la Ciudad Universitaria, se edita la Revista de Derecho.

En 1970 a iniciativa del Abogado Enrique Flores Lanza, se crea el Instituto de Investigaciones Jurídicas bajo la dirección del abogado Adolfo León Gómez. El Instituto desde su creación a la fecha ha tenido nueve directores, entre sus objetivos está realizar investigación científica. el Instituto de investigación Jurídica ha participado en la elaboración de varios Anteproyectos de Ley.

En 1972 fue aprobada la regulación de la carga académica basada en el índice académico, los estudiantes que habían obtenido un índice académico de $60 \%$ $69 \%$ solo podrían inscribir 15 unidades valorativas; de 50-59 \%, 12 unidades valorativas y menos de $40 \%$ solo podían inscribir 10 unidades valorativas. Se llevó a cabo una reforma al Reglamento de Exámenes de la Facultad; modificando la 
forma de exámenes generales públicos de tesis, practicándose en la misma forma el examen privado.

En 1975 se celebró el Primer Seminario Nacional de Derecho Internacional "Luís Arturo Zacapa" y además se celebró la Primera Jornada de Derecho de Menores.

En 1976 se llevó a cabo el Sub Encuentro de Facultad, como resultado del Encuentro se formularon conclusiones inherentes al quehacer académico que servirían de pauta a la transformación general de la Universidad.

En 1978 se reformaron los planes de estudio bajo el marco de las resoluciones tomadas en el Primer Encuentro de la Comunidad Universitaria y el Primer Encuentro de la Facultad de Ciencias Jurídicas y Sociales. Las directrices seguidas pretendían lograr que el profesional del Derecho fuera en su profesión:

1. Orientador en los asuntos de interés nacional.

2. Defensor honesto de los intereses que le confíen

3. Promotor del cambio de las estructuras sociales en beneficio de la nación.

4. Un factor que contribuya con sus conocimientos, para que en el país prevalezca un orden permanente de Libertad, Derecho y Justicia.

En el año de 1978 la Carrera de Derecho cuenta con 1795 estudiantes que representan el $9.6 \%$ del total matriculados. El número de Docentes asignados era 49 y el total de graduados hasta 1978 es de 1,759.

De 1978 hasta 1990 Para optar al grado de Licenciado en Ciencias Jurídicas y Sociales era necesario cumplir con los siguientes requisitos:

1. Haber aprobado 195 unidades valorativas.

2. Haber hecho un año de práctica en un Bufete dirigido por un Abogado autorizado para tal fin por la Facultad de Ciencias Jurídicas y Sociales.

3. Haber realizado servicio social obligatorio.

4. Haber aprobado un examen General Privado.

5. Aprobar un examen de sustentación de Tesis.

La regulación de la carga académica esta en relación directa con el índice académico obtenido en su último semestre de estudios, o sea que los estudiantes 
para poder matricularse debían cumplir la siguiente tabla de índice según las notas de cada uno.

\begin{tabular}{l|l}
\hline Con índice menor de $49 \%$ se inscribían & 11 Unidades Valorativas \\
\hline Con índice de $50-59 \%$ & 13 Unidades Valorativas \\
\hline Con índice de $60-69 \%$ & 15 Unidades Valorativas \\
\hline Con índice de $70-79 \%$ & 18 Unidades Valorativas \\
\hline Con índice de $80-89 \%$ & 20 Unidades Valorativas \\
\hline Con índice de $90-100 \%$ & 23 Unidades Valorativas \\
\hline \hline
\end{tabular}

A partir de 1992 fue suprimido el examen privado para los que terminaban la Carrera de Derecho.

En el año de 1998 fue suprimido el Examen General de Tesis a partir de ese momento los egresados podían realizar una monografía de su práctica supervisada como requisito último de graduación.

A partir del año 2006 se suprime la monografía y en vez ese requisito se les exige llevar la asignatura seminario taller de investigación jurídica, que hasta la fecha, es un requisito obligatorio para todos los que están a punto de egresar de la UNAH.

A partir del 2008 la Facultad de Derecho ha estado elaborando las nuevas reformas al Plan de estudios del 2003, dichas reformas tendrán vigencia una vez que se hayan aprobado en el Consejo Universitario.

\section{CAPÍTULO II}

\section{OBJETIVOS DE LA CARRERA DE DERECHO}

Actualmente los objetivos de la Carrera de Ciencias Jurídicas son los siguientes:

\section{A. Objetivos Generales}

- Formar integralmente los profesionales del Derecho que Honduras necesita para su desarrollo social y económico en un contexto democrático y parti- 
cipativo.

- Formar profesionales que contribuyan al desarrollo humano sostenible, a la defensa del medio ambiente y al combate contra la pobreza.

- Inculcar en el profesional del Derecho una verdadera conciencia organizativa con criterio jurídico.

- Capacitar al profesional para ejercer su profesión en el más amplio sentido de función social.

- Formar un profesional capacitado para dar soluciones científicas y prácticas a los problemas que se planteen en el campo jurídico.

- Estimular la vocación para la investigación y solución de problemas jurídiconacionales.

- Propiciar la formación de una conciencia ética en la profesión y fomentar el espíritu de solidaridad humana y social.

- Promover y fortalecer la aptitud y conciencia de lucha por los valores de justicia, libertad y democracia.

\section{B. Objetivos Específicos de la Carrera}

- Formar profesionales con conocimientos fundamentales en todos los aspectos esenciales del Derecho.

- Orientar el proceso de formación del profesional hacia la obtención de conocimientos sintéticos y analíticos de las disciplinas jurídicas, estableciendo un adecuado balance entre lo teórico y lo práctico.

- Aplicar las bases fundamentales del humanismo democrático que postula la Constitución, la Teoría General del Derecho y las ramas más importantes del Derecho positivo vigente.

- Identificar las funciones que debe asumir posteriormente el profesional mediante el conocimiento de disciplinas humanísticas, así como de materias de integración del Derecho en una perspectiva de preparación sólida y coherente del estudiante.

- Formar profesionales que aúnen al conocimiento de las leyes y doctrinas generales, la formación humanista e investigativa.

- Formar ciudadanos conscientes de su misión como profesionales del Derecho, aptos para aconsejar, conciliar y defender los derechos de sus representados. 


\section{CAPÍTULO III}

\section{ANTECEDENTES DE LOS PLANES DE ESTUDIO DE LA CARRERA DE DERECHO}

1. El Primer Plan de Estudios fue ratificado el 20 de septiembre de 1847, con las materias siguientes: Gramática Castellana, Matemáticas, Gramática Latina, Filosofía, Derecho Canónico, Derecho Civil, Medicina y Física y Mineralogía. Estas últimas dos se impartieron varios años después.

2. Durante la Reforma Liberal del Doctor Marco Aurelio Soto, (1877-1883) la Universidad fue objeto de reformas educativas, mediante la puesta en vigencia del nuevo Código de Educación, se creó la Facultad de Jurisprudencia y Ciencias Políticas en el año de 1882, cuyo Plan de Estudios comprendía asignaturas referidas principalmente al Derecho Civil, Derecho Internacional, Derecho Político, Derecho Comercial, Derecho Penal y Procedimientos y Práctica en los Juzgados de Letras, ese nuevo Plan de Estudios resultó ser una novedad, pues le proporcionaba al nuevo Licenciado un conocimiento de las Ciencias Jurídicas, enmarcado en la Filosofía Positiva, suprimiendo el Latín, los Cánones y la Teología, las Matemáticas y la Filosofía que eran la base de la antigua Carrera de Derecho.

3. Con la emisión de nuevos Códigos y Leyes de Menores en el año de 1906, se reforma el Plan anterior y tuvo vigencia hasta el año de 1969.

4. A partir de la década de 1970, el Plan de Estudios incorporó más asignaturas habiendo tenido reformas en 1978.

5. Entre 1991-1998 se eliminaron los exámenes generales privado y público respectivamente, con el objeto de facilitar la obtención del título a los alumnos que hubieran concluido el pensum académico.

6. En el segundo semestre del año 2003, entra en vigencia el nuevo Plan de Estudios de la Carrera de Derecho, con reformas cuantitativas y cualitativas, donde se han incorporado nuevas asignaturas acerca de materias que son necesarias en la formación del estudiante, tales como Interpretación Jurídica, Derecho de la Niñez y la Adolescencia, Propiedad Intelectual y otras, y se han establecidos como obligatorias las asignaturas de Ética General, Lógica General. 


\section{CAPÍTULOIV}

\section{EL PLAN DE ESTUDIOS DEL 2003}

El objeto principal de revisar y actualizar el Plan de Estudios de la Carrera de Derecho va orientado fundamentalmente a formar un profesional portador de valores, con sólidos principios éticos, morales y cívicos que crucen en todo momento su calificado y pertinente proceso de formación humana-profesional con pleno dominio de las disciplinas que constituyen la columna vertebral de la profesión del Derecho, no solo que ejerza con sólida capacidad y credibilidad, sino también para que posteriormente acceda a conocimientos, preparación y una profesionalización más especializada. El Nuevo Plan de Derecho 2003, fue aprobado por Acuerdo No. 027-2003 en el Acta No. 760 del 2 de marzo del 2003, Inscrito con el No. 25, Tomo VI del Libro de Registros de Planes de Estudio que Ileva la Secretaria General de la UNAH, entrando en vigencia el segundo semestre del año 2003, el que está estructurado de la siguiente manera:

\section{ASIGNATURAS GENERALES DE CARÁCTER OBLIGATORIO}

Con el objeto de dar una base al estudiante se les exige ocho (8) asignaturas Generales de las Ciencias Sociales y una asignatura electiva de las artes o deportes.

\section{ASIGNATURAS ESPECÍFICAS PROFESIONALIZANTES}

Cuarenta y nueve (49) asignaturas que buscan dar al estudiante una orientación teórica y práctica, para que sea capaz de interpretar y aplicar las normas jurídicas al caso concreto, asimismo para que pueda continuar su formación después de haber obtenido su Licenciatura. Estas asignaturas se dividen el Derecho Público y Derecho Privado, se han incorporado materias como Derecho Ambiental, Derecho Forestal y de Aguas, que se hacían necesarias en un país de eminente vocación forestal, además se estudian materias de Derecho Internacional Público y de Derecho Internacional Privado, con el objeto que el estudiante pueda insertarse en un mundo cada vez más globalizado y competitivo.

\section{MÓDULOS}

Una vez concluidas las clases profesionalizantes, el estudiante debe cursar nueve 
(9) módulos talleres, los cuales tienen como propósito básico, aplicar el conocimiento adquirido a través de los distintos procedimientos prácticos, que se Ilevan a cabo en los tribunales de la República.

Con la reforma del Plan de Estudios estos nueves módulos ahora denominados talleres o Laboratorios jurídicos se organizan en pasantías con una duración temporal de 7 semanas cada una.

\section{Pasantía A}

1. Taller de Práctica Procesal Civil
2. Taller de Práctica Procesal Laboral
3. Taller de Criminalística

\section{Pasantía B}

1. Taller de Práctica Procesal Penal

2. Taller de Práctica Procesal Administrativa

3. Taller de Métodos Alternos de Solución de Controversias

\section{Pasantía C}

1. Taller Práctica Judicial Internacional

2. Taller de Derecho Notarial y Derecho Registral

3. Taller de Justicia Constitucional

\section{SUPRESIÓN DE LAS ORIENTACIONES}

En el nuevo Plan de Estudios 2003 se suprimieron las orientaciones que han sido 
una opción de especialización de la carrera de Derecho, porque el modelo se agotó en la práctica sin resultados significativos en el orden de la realidad social; y además porque la finalidad u objetivo de las orientaciones puede fortalecerse y ampliarse por otros medios que permitan al educando por una parte tener una formación más coherente y concentrada con el plexo de materias fundamentales que le den mayor cobertura, y consistencia profesional para que posteriormente ya graduado curse las especialidades de su preferencia de acuerdo con las opciones de especialidades, maestrías y doctorados.

El Plan de Estudios del 2003 fue aprobado con cincuenta y ocho (58) asignaturas, más nueve módulos haciendo un total de 67 asignaturas, además está estructurado en catorce semestres, en el primer semestre el estudiante cursara las asignaturas de formación general, en el segundo se ofrece un bloque de cuatro asignaturas, del Tercer al Décimo Primer Semestre, se cursan las asignaturas medulares de la carrera de Derecho, su secuencia es en base a requisitos, del Décimo Segundo al Décimo Tercer Semestre los nueve módulos de práctica que el estudiante los podrá cursar una vez que haya terminado de cursar las 58 asignaturas, en el Décimo Cuarto Semestre el estudiante puede cursar la práctica forense obligatoria y la práctica supervisada.

\section{Resumen del Plan de Estudios 2003 de la UNAH}

\begin{tabular}{|l|c|c|}
\hline & $\begin{array}{c}\text { Número de } \\
\text { Asignaturas }\end{array}$ & $\begin{array}{c}\text { Unidad } \\
\text { Valorativa }\end{array}$ \\
\hline $\begin{array}{l}\text { Asignaturas de Formación } \\
\text { General }\end{array}$ & 09 & 32 \\
\hline $\begin{array}{l}\text { Asignaturas Específicas } \\
\text { Profesionalizantes Básicas }\end{array}$ & 49 & 190 \\
\hline $\begin{array}{l}\text { Módulos de Práctica Procesal } \\
\text { Total }\end{array}$ & 9 & 36 \\
\hline \hline
\end{tabular}

\section{A. PROCEDIMIENTO DE ADMISIÓN}

El proceso de admisión en la Facultad de Ciencias Jurídicas ha tenido en los últimos tiempos una serie de reformas que a continuación se describen desde su creación hasta el 2003 de la siguiente manera: 
a. De libre admisión desde su creación hasta el año 2002, donde cualquier persona se podía matricular en la Carrera de Derecho, con solo cumplir los requisitos de matrícula para la admisión en la UNAH.

b. A partir del 2003 la admisión se realiza a través de un examen de admisión interno, realizado por la facultad de Ciencias Jurídicas en el cual se evaluaban las siguientes áreas del conocimiento: Español, Conocimientos Generales, Estadística, Habilidad Numérica, Razonamiento en Aritmética, Estadística, Álgebra y Geometría etc. Y se realizaba una prueba psicosomática la que era realizada por profesores de la Facultad de Psicología.

c. A partir del 2007 se implementa la admisión a través de un examen de aptitudes y conocimiento básico, aplicado por la Universidad Nacional Autónoma de Honduras.

Este examen surge con la Reforma a las Normas Académicas, para el ingreso a la UNAH. Pero es a partir del primer semestre del año 2007 que el examen de admisión interno de la Facultad de Ciencias Jurídicas fue sustituido por la Prueba de Aptitud Académica, que realiza el sistema de Admisión de la UNAH, válido para todas las carreras, el que evalúa a los estudiantes en habilidad numérica que comprende: aritmética, estadística álgebra y geometría, y habilidad verbal donde los aspirantes deben saber interpretar la lectura, deben conocer los sinónimos y los antónimos ${ }^{20}$.

\section{B. OBJETIVOS DEL PLAN DE ESTUDIOS DEL 2003}

El graduado en la Licenciatura en Ciencias Jurídicas estará en capacidad de:

1) Sustentar una concepción integral del Derecho desde los puntos de vista filosófico, científico, político y social.

2) Interpretar los principios fundamentales de la Ciencia del Derecho, referidos particularmente al ámbito nacional público y privado.

3) Manejar la metodología global de la Ciencia del Derecho y suscontenidos

${ }^{20}$ Sistema de Admisión de la UNAH. 
materiales y los procedimientos jurídicos básicos de su aplicación en la práctica social.

4) Aportar respuestas de solución a problemas tecnológicos y operativos específicos que se dan en el campo profesional.

5) Estructurar una metodología general de investigación científica tendiente a la exploración de aspectos críticos en la dimensión universal de las ciencias jurídicas y en los medios del sistema de leyes del país.

6) Participar creativamente en los procesos de actualización del ordenamiento jurídico hondureño, lo mismo que en los proyectos de transferencia tecnológica legislativa de otros Estados hacia el nuestro.

7) Contribuir a la integración de equipos profesionales interdisciplinarios que promuevan la gestación de Ciencia y Tecnología Jurídica con proyección nacional.

8) Actuar en consonancia con la necesidad de compatibilizar la actividad jurisprudencial con un espíritu de renovación permanente y de identidad nacional, acorde con los avances científico - tecnológicos y las exigencias del desarrollo económico y social del país.

9) Observar, en armonía con el objetivo anterior, una conducta profesional consecuente en el marco planificado de las acciones jurídicas dentro de su ámbito de su competencia.

10) Saber equilibrar la Justicia con el Derecho en el tratamiento de las causas que se le presenten, en los estrados pertinentes.

\section{CAPÍTULO V}

\section{ANÁLISIS COMPARATIVO DE LA MATRÍCULA DE LA CARRERA DE DERECHO EN LA UNAH Y LAS UNIVERSIDADES PRIVADAS}

Con el presente cuadro conoceremos el ingreso de estudiantes de primer ingreso a la Facultad de Derecho de la UNAH, durante los años del 2003 al 2009 inclusive.

\section{a). Número de estudiantes matriculados en la Carrera de Derecho durante los últimos cinco años en la UNAH}




\begin{tabular}{|l|c|c|c|c|}
\hline Año & Período & 1er. Ingreso & Reingreso & Total \\
\hline 2003 & I & 714 & 6,642 & $\mathbf{7 , 3 5 6}$ \\
\hline 2003 & II & 40 & 6,634 & $\mathbf{6 , 6 7 4}$ \\
\hline 2003 & III & 206 & 3,371 & $\mathbf{3 , 5 7 7}$ \\
\hline 2004 & I & 32 & 5,966 & $\mathbf{5 , 9 9 8}$ \\
\hline 2004 & II & 12 & 5,532 & $\mathbf{5 , 5 4 4}$ \\
\hline 2004 & III & 31 & 3,191 & $\mathbf{3 , 2 2 2}$ \\
\hline 2005 & I & 13 & 5,082 & $\mathbf{5 , 0 9 5}$ \\
\hline 2005 & II & 10 & 4,444 & $\mathbf{4 , 4 5 4}$ \\
\hline 2005 & III & 0 & 2,789 & $\mathbf{2 , 7 8 9}$ \\
\hline 2006 & I & 13 & 4,165 & $\mathbf{4 , 1 7 8}$ \\
\hline 2006 & II & 2 & 3,146 & $\mathbf{3 , 1 4 5}$ \\
\hline 2006 & III & 11 & 3,651 & $\mathbf{3 , 6 6 2}$ \\
\hline 2007 & I & 146 & 3,470 & $\mathbf{3 , 6 1 6}$ \\
\hline 2007 & II & 0 & 2,396 & $\mathbf{2 , 3 9 6}$ \\
\hline 2007 & III & 17 & 3,016 & $\mathbf{3 , 0 3 3}$ \\
\hline 2008 & I & 122 & 2,896 & $\mathbf{3 , 0 1 8}$ \\
\hline 2008 & II & 94 & 1,938 & $\mathbf{2 , 0 3 2}$ \\
\hline 2008 & III & 154 & 2,387 & $\mathbf{2 , 5 4 1}$ \\
\hline 2009 & I & 117 & 2,276 & $\mathbf{2 , 3 9 3}$ \\
\hline \hline
\end{tabular}

Como podemos observar en el cuadro anterior la matricula en la Facultad de Derecho de la UNAH, durante el Primer semestre del 2003 para los alumnos de primer ingreso de la carrera de Derecho, fue de setecientos catorce (714) estos fueron los últimos alumnos de libre ingreso, durante el segundo semestre del mismo año cuando entra en vigencia el Nuevo Plan de Estudios 2003 y los aspirantes hicieron examen de admisión interno en la Facultad de Derecho son cuarenta (40) en el Tercer semestre la matrícula es de doscientos seis (206), en el año 2004 la matrícula es de setenta y cinco (75) estudiantes, durante el 2005 la matrícula de primer ingreso fue de veintitrés (23) estudiantes, en el 2006 fue de veintiséis (26).

Del año 2007 en adelante el examen de admisión interno de la Facultad de Derecho, fue sustituido por la Prueba de aptitud Académica, la matrícula de primer ingreso para los estudiantes de Derecho es de Ciento sesenta y tres (163) en el 2008 fue de trescientos setenta (370) alumnos, en el primer semestre del 2009 fue de ciento diez y siete (117) alumnos ${ }^{21}$.

${ }^{21}$ Oficina de Registro 


\section{b). Matrícula de los estudiantes de Derecho de la UNAH, en comparación a la matrícula de derecho en las Universidades privadas.}

Con el nacimiento de universidades privadas y la creación de la Carrera de Derecho en cada una de ellas podemos observar como la matrícula de la carrera de Derecho en la Universidad Nacional Autónoma de Honduras baja de manera considerable, y la matrícula de algunas Universidades privadas crece.

Durante el año 2002 la matricula en la Universidad Nacional Autónoma de Honduras fue de nueve mil novecientos sesenta y cinco $(\mathbf{9 , 9 6 5 )}$ estudiantes, en la Universidad José Cecilio del Valle fue de sesenta y seis (66), en la Universidad de San Pedro Sula fue de trescientos cincuenta y seis (356), Universidad Tecnológica Centroamericana veintinueve (29), Universidad Católica de Honduras cuatrocientos veintiún (421), Universidad Tecnológica de Honduras ciento treinta (130).

En el año 2003 la matricula en la Universidad Nacional Autónoma de Honduras fue de diez mil ciento quince $(\mathbf{1 0 , 1 1 5})$ estudiantes, en la Universidad José Cecilio del Valle fue de cincuenta y nueve (59), en la Universidad de San Pedro Sula fue de trescientos veintisiete (327), Universidad Tecnológica Centroamericana cincuenta y un (51), Universidad Católica de Honduras seiscientos cinco (605), Universidad Tecnológica de Honduras doscientos noventa y siete (297).

En el 2004 la matricula en la Universidad Nacional Autónoma de Honduras fue de ocho mil treinta y ocho $(\mathbf{8 , 0 3 8})$ estudiantes, En la Universidad José Cecilio del Valle fue de sesenta y siete (67), En la Universidad de San Pedro Sula fue de trescientos veintisiete (327), Universidad Tecnológica Centroamericana ochenta y tres (83), Universidad Católica de Honduras setecientos setenta (770), Universidad Tecnológica de Honduras cuatrocientos noventa y ocho (498).

En el 2005 la matricula en la Universidad Nacional Autónoma de Honduras fue de seis mil quinientos treinta y cinco $(\mathbf{6 , 5 3 5 )}$ estudiantes, En la Universidad José Cecilio del Valle fue de setenta y nueve (79), En la Universidad de San Pedro Sula fue de trescientos cuarenta y cuatro (344), Universidad Tecnológica Centroamericana ciento siete (107), Universidad Católica de Honduras setecientos setenta (770), Universidad Tecnológica de Honduras setecientos cincuenta y cuatro (754). 
En el 2006 la matricula en la Universidad Nacional Autónoma de Honduras fue de cinco mil doscientos cuatro $(\mathbf{5}, \mathbf{2 0 4})$ estudiantes, En la Universidad José Cecilio del Valle fue de cuarenta y nueve (49), En la Universidad de San Pedro Sula fue de cuatrocientos (400), Universidad Tecnológica Centroamericana ciento cincuenta (150), Universidad Católica de Honduras mil noventa y dos (1,092), Universidad Tecnológica de Honduras mil ciento setenta y cinco $(\mathbf{1 , 1 7 5})$.

En el 2007 la matricula en la Universidad Nacional Autónoma de Honduras fue de Tres mil setecientos treinta y tres $(3,733)$ estudiantes, En la Universidad José Cecilio del Valle fue de Cuarenta y cinco (45), En la Universidad de San Pedro Sula fue de trescientos Noventa (390), Universidad Tecnológica ciento ochenta y ocho (188), Universidad Católica de Honduras Mil Trescientos diez y nueve (1,319 Universidad Tecnológica de Honduras Mil Ochocientos sesenta y tres $(\mathbf{1 , 8 6 3 )}$.

En el 2008 la matricula en la Universidad Nacional Autónoma de Honduras fue de Dos mil Quinientos cuarenta y un $(\mathbf{2}, \mathbf{5 4 1})$ estudiantes, En la Universidad José Cecilio del Valle fue de sesenta y nueve (69), En la Universidad de San Pedro Sula fue de trescientos noventa y cinco (395), Universidad Tecnológica Centroamericana doscientos cincuenta y un (251), Universidad Católica de Honduras Mil Trescientos cuarenta y uno (1,341), Universidad Tecnológica de Honduras Dos Mil ciento veinte (2120) y la Universidad Cristiana de Honduras treinta y tres (33).

\section{CAPÍTULO VI}

\section{ALGUNOS FACTORES QUE SEGÚN LOS ESTUDIANTES INCIDEN LA DISMINUCIÓN DE LA MATRÍCULA EN LA CARRERA DE DERECHO DE LA UNAH}

Después de haber realizado algunas entrevistas en grupo a estudiantes de Derecho del Plan Nuevo 2003, ellos son de la opinión que los factores que inciden en la matrícula de la Carrera de Derecho son los siguientes:

1. Los alumnos que ingresaron a la Universidad a estudiar la Carrera de Derecho, con examen de admisión interno de la Facultad de Derecho, fueron menos en los tres (3) años que estuvo vigente dicho examen, que los alumnos que han ingresado a la Universidad a estudiar Derecho con la prueba de Actitud 
académica, que es válida para todas las carreras de la UNAH.

2. El nuevo Plan de estudios de Derecho del 2003 es muy largo y para algunos estudiantes que vienen a clases desde Danlí, Santa Ana, Ojojona y otros lugares cercanos los costos de cada año son onerosos para sus padres y para ellos mismos. Las primeras cuatro (4) clases de la Facultad de Derecho, Metodología y Técnicas de la Investigación, Informática Jurídica, Lógica Jurídica, Ética Jurídica e Interpretación Jurídica, sean en bloque ya que si un estudiante no aprueba una de las cuatro no puede avanzar, ya que las cuatro son requisito para cursar las tres (3) asignaturas que continúan según el Plan de Estudios, y que son: Derecho Romano, Introducción al Estudio del Derecho y Teoría General del Estado.

3. En algunos semestres no se imparten todas las asignaturas y por lo tanto los estudiantes no avanzan, ya que algunas asignaturas solamente se imparten por la mañana y otras por la tarde y tienen que venir a la Universidad dos veces, causando más gasto al estudiante.

4. Los estudiantes que han aprobado asignaturas del Nuevo Plan de Estudios de Derecho 2003, manifiestan que algunas de estas asignaturas son repetitivas dentro del Pensum Académico.

\section{CONCLUSIÓN}

Después de haber realizado este trabajo de Investigación se ha llegado a la conclusión siguiente: El Nuevo Plan de Estudios de la Carrera de Derecho de la Facultad de Ciencias Jurídicas del 2003, de la Universidad Nacional Autónoma de Honduras si es uno de los factores que inciden en la disminución de la matrícula y la permanencia en la misma.

\section{RECOMENDACIONES}

EI Nuevo Plan de Estudios de la Carrera de Derecho del 2003, de la UNAH, debe ser revisado y modificado para que se encuentre acorde a la realidad nacional. 
Las primeras cuatro asignaturas que se sirven la Facultad de Derecho de la UNAH, deben ser desbloqueadas para no atrasar a los estudiantes.

Deben existir horarios flexibles por la mañana y por la tarde, para que puedan matricular sus asignaturas en forma continua, además se debe trabajar en la Facultad de Derecho con un solo Plan de Estudios.

\section{BIBLIOGRAFÍA}

Reina Idiáquez, Jorge Arturo, Historia de la UNAH en su Época Autónoma, Tomos I y II.

Plan de Estudios de Derecho de la Universidad Nacional Autónoma de Honduras, Aprobado por Acuerdo No.027-2003 en el Acta No.760 del 2 de marzo del 2003, inscrita con el No. 25, Tomo VI del Libro de Registro de Planes de Estudio que lleva la Secretaria General de la UNAH.

Plan de Estudios de Derecho de la Universidad José Cecilio del Valle (Reformado) RPR-165-02-05 Aprobado por Acuerdo No. 1291 del Acta No. 174-04 de la Dirección de Educación Superior.

Plan de Estudios de Derecho de la Universidad de San Pedro Sula RP-5007-94 Aprobado por Acuerdo No. 170-53-93 de la Dirección de Educación Superior. Plan de Estudios de Derecho de la Universidad Tecnológica Centroamericana $R P(R)$ 201-1206 Aprobado por acuerdo 1693 del Acta No. 196-06 de la Dirección de Educación Superior.

Plan de Estudios de Derecho de la Universidad Católica de Honduras RP(R) 16801-04 aprobado por Acuerdo No. 1127 del Acta No.160-03 de la Dirección de Educación Superior.

Plan de Estudios de Derecho de la Universidad Tecnología de Honduras RP(R) 204-02-05 Aprobado por Acuerdo No. 1292 del Acta No. 174-04 de la Dirección de Educación Superior.

RP - Registro Plan.

$\mathrm{RP}(\mathrm{R})$ - Registro de Plan reformado. 